\title{
Photocatalytic degradation of natural organic matter: Kinetic considerations and light intensity dependence
}

\author{
Ceyda Senem Uyguner and Miray Bekbolet \\ Bogazici University, Institute of Environmental Sciences, 34342, Bebek, Istanbul, Turkey
}

\begin{abstract}
The current study was conducted to investigate the photocatalytic degradation kinetics of humic acid at different light intensities using commercial $\mathrm{TiO}_{2}$ powders. The pseudo first order kinetic model and Langmuir-Hinshelwood (L-H) rate equation in modified forms were used to compare the photocatalytic activities of $\mathrm{TiO}_{2}$ materials as a function of light intensity. Under constant irradiation conditions, the pseudo first order reaction rates as well as L-H rates were found to be decreasing in the following trend; Degussa P-25, Millennium PC-500 and Millennium PC-100. The pseudo first order rate constants showed the same decreasing trend as the pseudo first order reaction rates while L-H rate constants exhibited a light intensity related change in the ordering of the photocatalysts. At the lowest light intensity, L-H rate constants decreased as follows: Millennium PC-500 > Millennium PC-100 > Degussa P-25. However, increasing the light intensity changed the order to; Millennium PC-100 > Millennium PC-500 > Degussa P-25 revealing the significance of the L-H adsorption constant. Under constant irradiation conditions, ionic strength dependent changes in the structure of humic acid did not alter degradation efficiency trend of the photocatalyst specimens and they were ordered such as; Degussa P-25 > Millennium PC-500 > Hombikat UV-100 > Millennium PC-100 > Merck. The results presented in this research also confirmed the effectiveness of Degussa P-25 as a photocatalyst for the degradation of humic acid.
\end{abstract}

\section{INTRODUCTION}

Typical surface waters contain natural organic matter (NOM) a large fraction of which is humic material being negatively charged due to the dissociation of carboxylic acid and hydroxy functional groups. Humic substances also possess amphipathic character owing to the presence of both hydrophobic and hydrophilic moieties. The acid insoluble fraction of humic material known as humic acids are the most important sunlight absorbers in natural waters that can photosensitize the oxidation of certain aquatic pollutants and biologically important substances. They constitute the major precursors of carcinogenic disinfection by-products that are produced during chlorination. Consequently, the reduction of the concentration of humic substances in drinking water supplies has become an important task.

In pursuit of efficient water treatment procedures, the study of light induced oxidation reactions catalyzed by titanium dioxide has received increased attention during the past decade. The main photochemical event in the $\mathrm{UV} / \mathrm{TiO}_{2}$ process is the formation of an electron hole pair through light absorption with an energy equal or greater than the bandgap, $\mathrm{E}_{\mathrm{bg}}$, which is $3.2 \mathrm{eV}$ $(390 \mathrm{~nm})$ for anatase and $3.05 \mathrm{eV}(420 \mathrm{~nm})$ for rutile. Energized electrons and holes can either recombine, dissipating energy or be available for redox reactions with electron donor or acceptor species adsorbed on the semiconductor surface. A series of oxidation/reduction processes involving species such as $\mathrm{O}_{2}, \mathrm{H}_{2} \mathrm{O}_{2}, \mathrm{O}_{2}{ }^{--}$ etc. may lead to complete degradation of organic compound to $\mathrm{CO}_{2}$ and inorganic ions [1, 2].
Currently, photocatalysis has been studied for the oxidative removal of the natural organic matter namely humic acids. Previously published works cover the effects of the presence of common anions and divalent cations, some transition metals such as $\mathrm{Cu}, \mathrm{Zn}, \mathrm{Cr}, \mathrm{Mn}$ and also the effect of the hypochlorite ion as well as other chlorinated oxyanions acting as electron acceptors [3-7]. In a recent study, the photocatalytic efficiencies of two titania brands; Degussa P-25 and Hombikat UV-100 were investigated for the decolorization of humic acid in aqueous solutions [8]. Despite the presence of other papers on the photocatalytic decomposition of humic acids, much less is known about how the photocatalytic degradation rate of humic acid at $\mathrm{TiO}_{2}$ /solution interface depends on the intensity of irradiation [9-15].

It is widely documented that aqueous phase photocatalytic oxidation reactions exhibit low quantum yields irrespective of irradiation conditions [1, 16-18]. When dealing with photocatalytic systems comprising the light intensity effects, besides information concerning the electrical power of the light source and the details of the geometry of the reactor, the importance of the experimental parameters like $\mathrm{pH}$, temperature, and initial concentration of the substrate should also be emphasized [1]. Therefore, a simple alternative method for comparing process efficiencies was introduced as relative photonic efficiency $\left(\xi_{\text {r }}\right)$ by Serpone and Emeline [19]. Assuming that the average molecular weight of humic acid is $50.000 \mathrm{~g} \mathrm{~mol}^{-1}$, the apparent quantum yield of humic acid $\left(10 \mathrm{mg} \mathrm{L}^{-1}\right)$ was reported as $0.206-0.245$ for $\mathrm{TiO}_{2}$ loadings in the range of $0.1-1.0 \mathrm{mg} \mathrm{mL}^{-1}$ [3]. 
Table 1. Properties of $\mathrm{TiO}_{2}$ specimens.

\begin{tabular}{lccc}
\hline Photocatalyst & Composition & Specific BET surface area $\left(\mathrm{m}^{2} \mathrm{~g}^{-1}\right)$ & Primary particle size $(\mathrm{nm})$ \\
\hline Degussa P-25 & $80 \%$ anatase $+20 \%$ rutile & 55 & 30 \\
Millennium PC-500 & $\geq 99 \%$ anatase & $>250$ & $5-10$ \\
Millennium PC-100 & $\geq 99 \%$ anatase & $80-100$ & $15-25$ \\
Hombikat UV-100 & $100 \%$ anatase & $>250$ & $<10$ \\
Merck & $100 \%$ rutile & 7.5 & $100-200$ \\
\hline
\end{tabular}

However, the determination of the actual quantum yield of humic acid was not possible due to the complex and undefined structural diversity of the substrate leading to a wide range of molecular size and weights [19]. Therefore, in this study rather than focusing on relative photonic efficiencies, a comparative evaluation of the efficiency of the system was based on relevant kinetic models.

The photocatalytic degradation characteristics of humic acid at different light intensities were investigated using various commercial $\mathrm{TiO}_{2}$ powders. The dependence of the kinetic parameters on the incident light intensity and the photocatalytic activities of $\mathrm{TiO}_{2}$ materials were compared in terms of pseudo first order and Langmuir-Hinshelwood kinetic models.

\section{MATERIALS AND METHODS}

2.1. Materials. Humic acid was supplied from Roth and a working solution of $10 \mathrm{mg} \mathrm{L}^{-1}$ was prepared by dilution of the stock solution $\left(1000 \mathrm{mg} \mathrm{L}^{-1}\right)$ with distilled deionized water for photocatalytic degradation experiments [20]. Humic acid solutions in the range of 5-20 mg L ${ }^{-1}$ were also prepared for Langmuir Hinshelwood kinetic studies.

Different types of commercial $\mathrm{TiO}_{2}$ powders namely; Degussa P-25, Hombikat UV-100, Millennium PC-500, Millennium PC-100 and Merck were used as the photocatalyst specimens for the degradation of humic acid. Specifications of the photocatalysts according to the manufacturer's data are given in Table 1.

2.2. Experimental. The detailed description of the photocatalytic degradation experiments was presented previously [8]. Centrifugation followed by filtration through $0.45 \mu \mathrm{m}$ membrane filters was used for the removal of $\mathrm{TiO}_{2}$. After each run, the absorption of the supernatant was determined spectrophotometrically at $254 \mathrm{~nm}$ using Shimadzu UV160A double beam spectrophotometer since; the absorbance value measured at $254 \mathrm{~nm}\left(\mathrm{UV}_{254}\right)$ is widely accepted as a surrogate parameter to explain total organic carbon (TOC) of humic acid. The initial $\mathrm{UV}_{254}$ absorbance value for $10 \mathrm{mg} \mathrm{L}^{-1}$ humic acid was $35.2 \mathrm{~m}^{-1}$ whereas the specific UV absorbance (SUVA) was calculated as $6.52 \mathrm{~m}^{-1} \mathrm{mg}^{-1} \mathrm{~L}$. The experimental error related with the spectrophotometric analysis was approximately $\pm 4 \%$. The photocatalytic degra- dation of humic acid was expressed in terms of $\mathrm{UV}_{254}$ throughout the study.

Potassium ferrioxalate actinometry was performed to measure the light intensity in the reaction medium as described in literature [21]. Photocatalytic degradation of humic acid was carried out at three different light intensities $\left(\mathrm{I}_{0}\right)$ in the range of $0.89 \mu \mathrm{E} \mathrm{min}^{-1}$ $3.44 \mu \mathrm{Emin}^{-1}\left(1.48 \times 10^{-2} \mu \mathrm{E} \mathrm{s}^{-1}-5.74 \times 10^{-2} \mu \mathrm{E} \mathrm{s}^{-1}\right)$. The initial $\mathrm{pH}$ of the solution was $6.50 \pm 0.20$.

\section{RESULTS AND DISCUSSION}

3.1. Kinetics of the degradation of humic acid. The organic compounds (e.g., humic acid, HA) present in the illuminated titania slurry undergo many chain and consecutive reactions. In an ideal case, all intermediate compounds are fully mineralized to carbon dioxide and water (eq. (1)).

$$
\mathrm{HA} \stackrel{h v / \mathrm{TiO}_{2}}{\longrightarrow} \mathrm{HA}_{\mathrm{Ox}} \longrightarrow \longrightarrow \mathrm{CO}_{2}+\mathrm{H}_{2} \mathrm{O}+\text { mineral acids }(1)
$$

Several kinetic models describing the mechanism of the photocatalytic oxidation reaction have been proposed starting with a simple pseudo first order reaction kinetic model leading to the application of the LangmuirHinshelwood (L-H) law [22, 23]. The pseudo first order reaction kinetics is expressed as follows;

$$
\text { Rate }=\mathrm{R}=-\mathrm{dC} / \mathrm{dt}=\mathrm{k} \mathrm{C}
$$

Where the terms represent the following meanings; R: pseudo first order rate $\left(\mathrm{m}^{-1} \mathrm{~min}^{-1}\right), \mathrm{C}$ : concentration of the substrate as expressed by $\mathrm{UV}_{254}\left(\mathrm{~m}^{-1}\right)$, t: irradiation time (min), k: pseudo first order reaction rate constant, $\left(\min ^{-1}\right)$.

On the other hand, Langmuir-Hinshelwood rate expression considers the dependencies of the photocatalytic reaction rates on the concentration of the substrates. Langmuir-Hinshelwood equation also covers the key role of adsorption constant, $\mathrm{K}_{\mathrm{LH}}$ on kinetics assuming that adsorption desorption kinetics is faster than the photochemical reaction.

$$
\text { Rate }=\mathrm{R}_{\mathrm{LH}}=\mathrm{k}_{\mathrm{LH}} \mathrm{K}_{\mathrm{LH}} \mathrm{C} /\left(1+\mathrm{K}_{\mathrm{LH}} \mathrm{C}\right)
$$

In the equation presented above, $\mathrm{R}_{\mathrm{LH}}$ is the $\mathrm{L}-\mathrm{H}$ rate $\left(\mathrm{m}^{-1} \mathrm{~min}^{-1}\right), \mathrm{k}_{\mathrm{LH}}$ is the $\mathrm{L}-\mathrm{H}$ rate constant that is 
Table 2. Pseudo first order kinetic model parameters for the photocatalytic degradation of humic acid (UV 254$)$ at three different light intensities.

\begin{tabular}{|c|c|c|c|c|c|c|}
\hline \multirow[b]{2}{*}{$\begin{array}{c}\mathrm{I}_{\mathrm{O}} \\
\mu \mathrm{E} \min ^{-1}\end{array}$} & \multicolumn{2}{|c|}{ Degussa P-25 } & \multicolumn{2}{|c|}{ Millennium PC-100 } & \multicolumn{2}{|c|}{ Millennium PC-500 } \\
\hline & $\begin{array}{c}\mathrm{k} \times 10^{-2} \\
\min ^{-1}\end{array}$ & $\begin{array}{c}\mathrm{R} \\
\mathrm{m}^{-1} \mathrm{~min}^{-1} \\
\end{array}$ & $\begin{array}{c}\mathrm{k} \times 10^{-2} \\
\min ^{-1}\end{array}$ & $\begin{array}{c}\mathrm{R} \\
\mathrm{m}^{-1} \mathrm{~min}^{-1} \\
\end{array}$ & $\begin{array}{c}\mathrm{k} \times 10^{-2} \\
\min ^{-1}\end{array}$ & $\begin{array}{c}\mathrm{R} \\
\mathrm{m}^{-1} \mathrm{~min}^{-1} \\
\end{array}$ \\
\hline 0.89 & 1.23 & 0.433 & 0.607 & 0.214 & 0.845 & 0.297 \\
\hline 2.09 & 1.96 & 0.689 & 0.729 & 0.257 & 0.882 & 0.311 \\
\hline 3.44 & 3.62 & 1.274 & 0.866 & 0.305 & 1.03 & 0.362 \\
\hline
\end{tabular}

Table 3. Langmuir-Hinshelwood kinetic model parameters for the photocatalytic degradation of humic acid (UV 254$)$ at three different light intensities, $\mathrm{R}_{\mathrm{LH}}$ values were calculated for $10 \mathrm{mg} \mathrm{L}^{-1} \mathrm{HA}$.

\begin{tabular}{cccccccccc}
\hline & \multicolumn{3}{c}{ Degussa P-25 } & \multicolumn{3}{c}{ Millennium PC-100 } & \multicolumn{3}{c}{ Millennium PC-500 } \\
\cline { 2 - 10 } $\mathrm{I}_{\mathrm{min}}{ }^{-1}$ & $\begin{array}{c}\mathrm{k}_{\mathrm{LH}} \\
\mathrm{m}^{-1} \mathrm{~min}^{-1}\end{array}$ & $\begin{array}{c}\mathrm{K}_{\mathrm{LH}} \\
\mathrm{m}\end{array}$ & $\begin{array}{c}\mathrm{R}_{\mathrm{LH}} \\
\mathrm{m}^{-1} \mathrm{~min}^{-1}\end{array}$ & $\begin{array}{c}\mathrm{k}_{\mathrm{LH}} \\
\mathrm{m}^{-1} \mathrm{~min}^{-1}\end{array}$ & $\begin{array}{c}\mathrm{K}_{\mathrm{LH}} \\
\mathrm{m}\end{array}$ & $\begin{array}{c}\mathrm{R}_{\mathrm{LH}} \\
\mathrm{m}^{-1} \mathrm{~min}^{-1}\end{array}$ & $\begin{array}{c}\mathrm{k}_{\mathrm{LH}} \\
\mathrm{m}^{-1} \mathrm{~min}^{-1}\end{array}$ & $\begin{array}{c}\mathrm{K}_{\mathrm{LH}} \\
\mathrm{m}^{2}\end{array}$ & $\begin{array}{c}\mathrm{R}_{\mathrm{LH}} \\
\mathrm{m}^{-1} \mathrm{~min}^{-1}\end{array}$ \\
\hline 0.89 & 0.342 & 0.898 & 0.332 & 0.384 & 0.0241 & 0.176 & 0.523 & 0.0258 & 0.249 \\
2.09 & 0.387 & 0.240 & 0.345 & 0.719 & 0.0135 & 0.232 & 0.577 & 0.0249 & 0.269 \\
3.44 & 0.514 & 0.120 & 0.415 & 0.887 & 0.0131 & 0.280 & 0.696 & 0.0239 & 0.318 \\
\hline
\end{tabular}

a surface rate constant covering the radiation absorption by the photocatalyst $\left(\mathrm{m}^{-1} \mathrm{~min}^{-1}\right)$ and $\mathrm{K}_{\mathrm{LH}}$ is the Langmuir constant reflecting the adsorption/desorption equilibrium between the substrate and the surface of the photocatalyst (m).

The modified L-H equation incorporating the light intensity can be rewritten as follows:

$$
\text { Rate }=\mathrm{R}_{\mathrm{mLH}}=\mathrm{k}_{\mathrm{mLH}} \mathrm{I}_{\mathrm{o}} \mathrm{K}_{\mathrm{LH}} \mathrm{C} /\left(1+\mathrm{K}_{\mathrm{LH}} \mathrm{C}\right)
$$

Where, $\mathrm{R}_{\mathrm{mLH}}$ and $\mathrm{k}_{\mathrm{mLH}}$ denote the modified $\mathrm{L}-\mathrm{H}$ rate $\left(\mathrm{m}^{-1} \mathrm{~min}^{-1}\right)$ and the modified $\mathrm{L}-\mathrm{H}$ rate constant $\left(\mathrm{m}^{-1} / \mu \mathrm{E}\right)$, respectively. $\mathrm{I}_{\mathrm{o}}$ is the light intensity $(\mu \mathrm{E}$ $\min ^{-1}$ ) and $\mathrm{k}_{\mathrm{mLH}}$ equals to $\mathrm{k}_{\mathrm{LH}} / \mathrm{I}_{\mathrm{O}}$.

The detailed deductions of the modified L-H reaction rate model covering the effects of light intensity have been well explained in literature [23-25].

3.2. Evaluation of the kinetic models. Photocatalytic degradation kinetics of humic acid under different light intensity conditions in the presence of Degussa P-25, Millennium PC-500 and Millennium PC100 were evaluated by pseudo first order (eq. (2)) and Langmuir-Hinshelwood kinetic models (eqs. (3)(4)). Due to the similar properties of Hombikat UV-100 and Millennium PC-500, and the low photocatalytic activity of Merck $\mathrm{TiO}_{2}$ comprising the pure rutile crystal structure, these specimens were not included in this section. Comparative results were previously reported on the photocatalytic decolorization of humic acids using Hombikat UV-100 and Degussa P-25 [8]. The relevant pseudo first order kinetic parameters of humic acid were calculated and presented in Table 2.

In general, for all the photocatalysts used, the pseudo first order rate constants increased with light intensity, suggesting that few oxidizing species were lost through recombination processes. At the lowest intensity value, the rate with P-25 was considerably higher than that observed with Millennium specimens. However, the difference between the rates related to Degussa P-25 and Millennium photocatalysts got larger with the increasing light intensity leading to remarkable changes up to four fold when $\mathrm{I}_{0}$ was $3.44 \mu \mathrm{E} \mathrm{min}^{-1}$. In the case of Millennium PC-500 the effect of light intensity on the reaction rate parameters was found to be the least significant with respect to the other $\mathrm{TiO}_{2}$ specimens. Simple pseudo first order removal rates of humic acid at three different light intensities were the most efficient in the presence of Degussa P-25 and could be presented in the decreasing order as; Degussa P-25 > Millennium PC-500 > Millennium PC-100. The high photocatalytic activity of Degussa P-25 could be explained by a synergistic interaction between rutile and anatase phases [26]. On the other hand, the L-H kinetic model parameters calculated at the specified light intensities for the $\mathrm{TiO}_{2}$ specimens were quite different from each other (Table 3).

For all the $\mathrm{TiO}_{2}$ specimens both rate constants $\left(\mathrm{k}_{\mathrm{LH}}\right)$ and the L-H rates $\left(\mathrm{R}_{\mathrm{LH}}\right)$ increased with intensifying light intensity. It is noteworthy that, even a slight increase in the intensity caused significant changes in the values of the adsorption constants $\left(\mathrm{K}_{\mathrm{LH}}\right)$ of Degussa P-25 and Millennium PC-100. On the other hand, in the case of Millennium PC-500, only a slight decrease of $\mathrm{K}_{\mathrm{LH}}$ was observed with the changing light intensity. The diverse nature of the photocatalyst used; i.e., Degussa P-25 being nonporous with its moderate surface area and mixed crystalline structure and the rest being porous and pure in crystalline structure may account for the differences of the adsorption constants. However, irrespective of the different properties of the photocatalysts used, 



Figure 1. The effect of light intensity on the $L-H$ rate constant, $\mathrm{k}_{\mathrm{LH}}(1 \mathrm{~A})$ and the effect of light intensity on the modified $L-H$ rate constant, $\mathrm{k}_{\mathrm{mLH}}(1 \mathrm{~B})$. Light intensity $\mathrm{I}: 0.89 \mu \mathrm{E} \mathrm{min}^{-1}$, Light intensity II: $2.09 \mu \mathrm{E} \mathrm{min}^{-1}$, Light intensity III: $3.44 \mu \mathrm{E} \mathrm{min}{ }^{-1}$.

substrate specific adsorption efficiencies have also been reported in literature [27].

The results in Table 3 show that for all the $\mathrm{TiO}_{2}$ specimens $\mathrm{K}_{\mathrm{LH}}$ values decrease with an increase in photon flux. A similar trend was reported by Emeline et al. for the photocatalytic degradation of phenol stating that $\mathrm{K}_{\mathrm{LH}}$ can not be considered as a Langmuir constant which reflects only the adsorption/desorption equilibrium $\left(\mathrm{K}_{\mathrm{LH}}=\mathrm{K}_{\mathrm{ads}} / \mathrm{K}_{\mathrm{des}}\right)$ [28]. In the same manner, comparing the simple phenol structure to that of humic acid, which is a complex polyfunctional macromolecule comprising phenolic as well as carboxylic moieties, the dependency of $\mathrm{K}_{\mathrm{LH}}$ on light intensity may be expected. In this study, the most drastic change in $\mathrm{K}_{\mathrm{LH}}$ values was attained with Degussa P-25. The change in the adsorption constants with the effect of light intensity suggests an alteration of the surface characteristics of $\mathrm{TiO}_{2}$ upon light irradiation depending on the mixed crystalline structure of Degussa P-25 (80\% anatase and 20\% rutile) versus pure anatase form of Millennium specimens (Table 1). Similar to the findings of others, the evaluation of the data to the L-H kinetic model for different light intensities revealed the adsorption related constant $\mathrm{K}_{\mathrm{LH}}$ as intensity dependent [25, 29].

In order to compare the L-H rates on a light intensity independent basis, modified $\mathrm{L}-\mathrm{H}$ rate constants $\left(\mathrm{k}_{\mathrm{mLH}}\right)$ were calculated according to eq. (4) and the results were presented in Figures 1A and 1B.

While the $\mathrm{k}_{\mathrm{LH}}$ constants increased linearly with light intensity, the modified $\mathrm{L}-\mathrm{H}$ rate constants $\left(\mathrm{k}_{\mathrm{mLH}}\right)$ showed a decreasing trend. This may be expected considering the reported findings that the L-H rate constant $\left(\mathrm{k}_{\mathrm{LH}}\right)$ is proportional to a power term of the light intensity [23, 28, 30-32]. Ollis et al. stated that at low light intensities the L-H rate would scale linearly with light intensity while it would depend on the square root of the light intensity at intensities greater than $7 \times 10^{-5} \mathrm{Em}^{-2} \mathrm{~s}^{-1}$ (1 UV sun) [30]. The dependencies of the reaction rates on the light intensity have been attributed to the increased rate of recombination of the photogenerated electron-hole pairs [18]. However, the experiments in this study were conducted at lower light intensities, i.e., $0.89 \mu \mathrm{E} \mathrm{min}^{-1}-3.44 \mu \mathrm{E} \mathrm{min}^{-1}$ compared to that reported in literature [30]. Hence, the photocatalytic degradation rate of humic acid as expressed by either pseudo first order or L-H kinetic models could be evaluated as a linear function of the light intensity. In the study of Palmer et al. a regional profile of light intensity effect on photocatalytic rate was observed [11]. A transition point of light intensity $\mathrm{I}_{\mathrm{O}}=1.22 \times 10^{-5} \mathrm{E} \mathrm{s}^{-1}$ was set below which the rate of initial degradation increased in proportion to light intensity. At higher light intensities $\left(\mathrm{I}_{\mathrm{O}}>1.22 \times 10^{-5} \mathrm{E} \mathrm{s}^{-1}\right)$ the initial photocatalytic rate of humic acid increased by a power of 0.12 where the effect of the rate of recombination became more prominent. The reported range of light intensity was $(0.3-20) \times 10^{-5} \mathrm{Es}^{-1}$ in comparison to the presented range $(1.48-5.74) \times 10^{-2} \mu \mathrm{Es}^{-1}$ which was in the linear region well below the transition point.

The comparison of the presented data in Tables 2 and 3 revealed that the enhancement in the removal rate of humic acid with increasing light intensity was prominent both in terms of pseudo first order and L$\mathrm{H}$ kinetic models. The results illustrated Degussa P-25 as the most efficient photocatalyst while the lowest removal efficiency was achieved with Millennium PC-100. For the Millennium $\mathrm{TiO}_{2}$ samples, the photocatalytic degradation rates showed an increasing trend with 

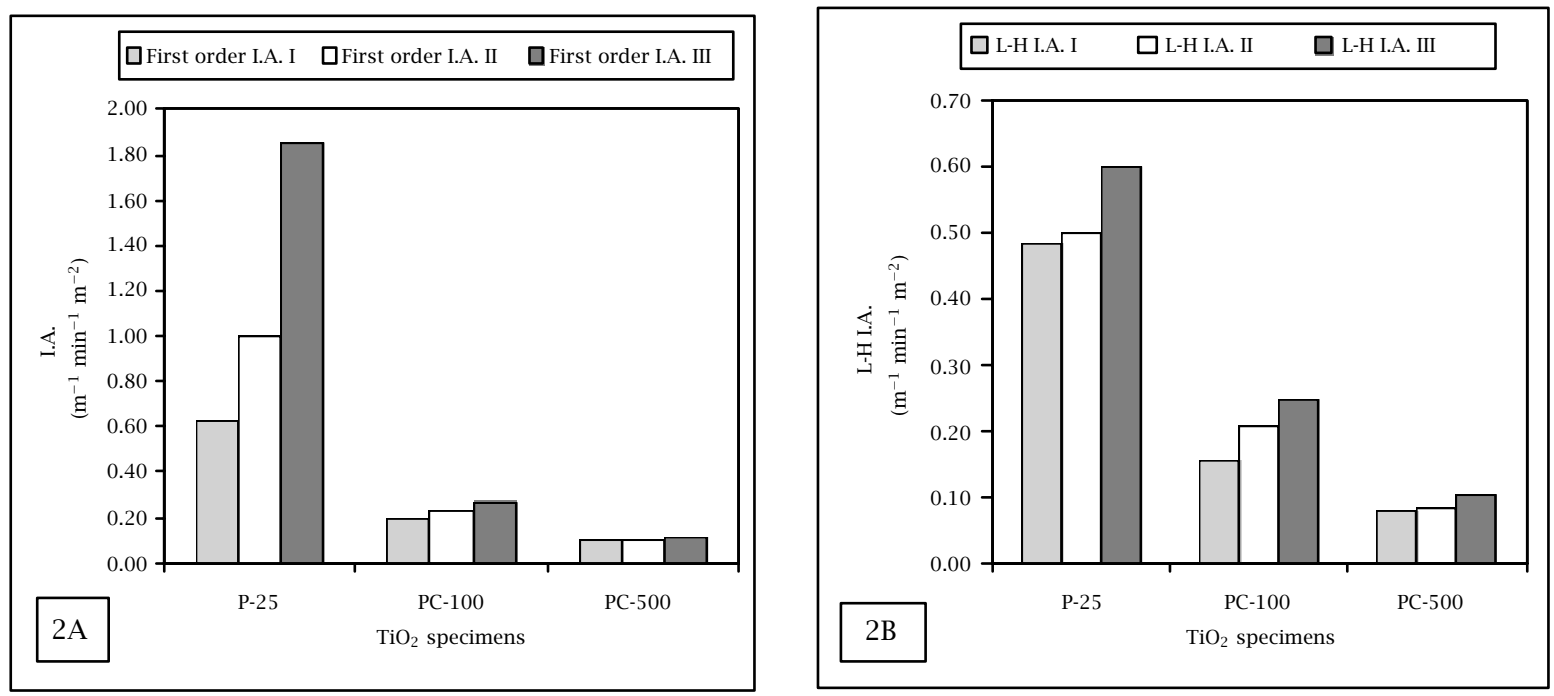

Figure 2. Pseudo first order intrinsic photocatalytic activities (I.A.) of $\mathrm{TiO}_{2}$ specimens (2A) and L-H intrinsic photocatalytic activities (L-H I.A.) of $\mathrm{TiO}_{2}$ specimens (2B) at different light intensities I: $0.89 \mu \mathrm{E} \mathrm{min}^{-1}$, II: $2.09 \mu \mathrm{E} \mathrm{min}^{-1}$, III: $3.44 \mu \mathrm{E} \mathrm{min}{ }^{-1}$.

respect to the specific surface area of the photocatalysts (Table 1). However, similar as well as contradictory results were also reported by other research groups revealing no clear relationship between BET surface of the photocatalyst and the photocatalytic degradation rates achieved under the specified conditions [27, 33]. It was emphasized that the relative photonic efficiency of a photocatalyst should depend mainly on the characteristics of the substrate used rather than the surface area. In order to eliminate the BET surface area factor and make the photocatalytic activity comparisons on a relative basis, the areal rates namely, the intrinsic photocatalytic activities (I.A.) were calculated by normalizing the corresponding rates with respect to the catalyst surface area (Figures 2A and 2B). The intrinsic photocatalytic activities calculated from pseudo first order and the L-H rates showed similarities for Millennium specimens. At the lowest light intensity conditions, I.A. values differed by $18 \%$ for Millennium PC-100. This difference was in the range of $16-12 \%$ for Millennium PC500. However, the ones determined for Degussa P-25 significantly varied from each other by $23-67 \%$.

It could be emphasized as a general trend that increasing the light intensity enhanced both pseudo first order and L-H intrinsic activities for the photocatalysts employed. In accordance with the results of pseudo first order and L-H kinetic models, the intrinsic photocatalytic activities presented in Figures 2A and 2B also confirmed Degussa P-25 as the most efficient photocatalyst. The high surface area of Millennium PC-500 did not lead to higher degradation rates. The results showed that the actual photocatalytic rate did not necessarily require the dependency on the BET catalyst surface area as expressed previously for Hombikat UV100 specimen [8]. Humic acids contain a variety of aromatic moieties and functional groups with different adsorption affinities. Electrostatic and/or chemical heterogeneities between these functional groups on a humic acid molecule lead to a non ideal adsorption behavior because of size incongruity and steric incompatibility. Humic acids can adsorb in loops or tails depending on the solution chemistry and thus may change the surface morphology of the oxide surface. On the other hand, the photoadsorption and photodegradation mechanisms are also known to be influenced by the structural characters in humic acids, which may substantially change as a result of the solution matrix. In the following section, the effect of ionic strength in relation to the photocatalytic degradation rate of humic acid is discussed.

\subsection{Effect of ionic strength on photocatalyst type} and reaction efficiency. Humic acids occur as long linear chains at high $\mathrm{pH}$ and low ionic strength due to the charge repulsion of deprotonated functional groups and transform into coiled spherical molecules at low $\mathrm{pH}$ and high ionic strength. Because of these structural changes, the effect of ionic strength on the photocatalytic degradation of humic acid was investigated using different types of commercial $\mathrm{TiO}_{2}$ powders namely; Degussa P-25, Hombikat UV-100, Millennium PC-500, Millennium PC-100 and Merck at constant light intensity. The experiments were conducted under different conditions; low ionic strength (I.S. $=0.01 \mathrm{M}$ ) and high ionic strength (I.S. $=0.1 \mathrm{M}$ ). To compare the photocatalytic removal efficiencies of different $\mathrm{TiO}_{2}$ types, 


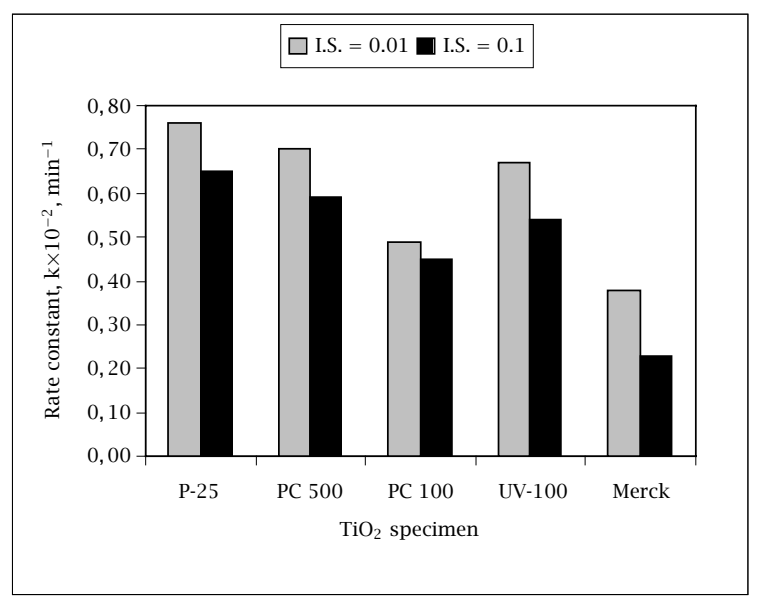

Figure 3. Ionic strength dependence of photocatalytic degradation rate of humic acid in the presence of different $\mathrm{TiO}_{2}$ specimens $\left(\mathrm{TiO}_{2}\right.$ loading: $0.25 \mathrm{mg} \mathrm{mL}^{-1}, \mathrm{I}_{0}=$ $0.89 \mu \mathrm{E} \mathrm{min}^{-1}$ ).

the pseudo first order rate constants were displayed in Figure 3. At constant irradiation $\left(\mathrm{I}_{\mathrm{o}}=0.89 \mu \mathrm{E} \mathrm{min}^{-1}\right)$ in the presence of $0.01 \mathrm{M}$ ionic strength the pseudo first order reaction rate constants for humic acid removal were found to be decreasing in the following order: Degussa P-25 > Millennium PC-500 $\approx$ Hombikat UV-100 > Millennium PC-100 > Merck. Regarding the similarities in both physical characteristics and adsorptive properties, PC-500 and UV-100 specimens exhibited proximate efficiency in photocatalytic degradation of humic acid.

Increasing the ionic strength to $0.1 \mathrm{M}$ did not change that order. The photodegradation rates obtained in the experiments at two different electrolyte concentrations were similar (same order of magnitude) with slightly lower rates for $0.1 \mathrm{M}$ ionic strength. For Degussa P-25, in the presence of 0.01 M ionic strength, $38 \%$ decrease was observed in the rate constant of humic acid compared to the one with no ionic strength. 10 fold increase in the background electrolyte concentration decreased the rate constant by an additional $14 \%$.

Comparison of the results in Figure 3 showed that the photocatalytic degradation of humic acid in the presence of Merck was more affected by ionic strength (almost 40\% decrease with 10 fold increase in ionic strength) than the other $\mathrm{TiO}_{2}$ specimens. The distinct properties of Merck with its single-crystalline, $100 \%$ rutile surface, relatively small surface area and high particle size might account for this difference. It was reported that the smaller the particle size of the $\mathrm{TiO}_{2}$ catalyst, the higher was the expected photocatalytic removal efficiency [34]. On the other hand, solute-surface interaction would be limited due to the lower surface area of Merck $\mathrm{TiO}_{2}$ and ionic strength dependent struc- ture of humic acid. It was also worth noting that the reaction rate of photodegradation depended on the concentration of surface hydroxyl groups. The concentration of $\mathrm{OH}$-groups present on the rutile surface was much less than that for anatase. Hence, the formation of $\mathrm{OH}$ radicals was limited as reflected in the calculated reaction rates.

The structure of dissolved humic acid is postulated to be a random coil with an electric charge that stems primarily from the ionization of carboxyl groups [35]. The humic acid molecules undergo conformational modifications when they are exposed to changes in either $\mathrm{pH}$ or ionic strength. Increasing the ionic strength increases the screening of charges and leads to molecular shrinkage. This is mainly the result of a combined effect of electrostatic repulsion between negatively charged groups that tends to expand the molecule, screening of electrical charges by supporting electrolyte ions that decreases the repulsion, and flexibility of the molecules to respond to expansioncontraction processes. Besides the structural effects, similar to our findings, the photocatalytic degradation of humic acid was reported to be slower in high salinity water than in low salinity water [13]. In the presence of high ionic strength the background concentration of inorganic salts compete for $\mathrm{OH}$ radicals and active sites of the photocatalyst thereby reducing the removal efficiency of humic acid.

Recent investigations revealed that photocatalyst activity was influenced by many factors such as crystal structure, particle size, BET surface area, adsorption capacity, the speed of charge transfer as well as the life span of $\mathrm{e}^{-} / \mathrm{h}^{+}$pairs $[19,34,36,37]$. Considering the presented consequences, these findings might address some explanations about the different photocatalytic activities of the different types of titania specimens used. In a previous study, Degussa P-25 with its mixed crystalline structure ( $80: 20$, anatase:rutile) and moderate surface area was shown to be a successful adsorbent and photocatalyst for humic acid decolorization [8]. Martin et al. showed that the high photoreactivity of P-25 was due to a slow electron/hole recombination rate [38]. Assuming that the rate of adsorption/desorption of substrate molecules and reaction intermediates was relatively slow in comparison to the formation rate of electron/hole pairs, one would expect higher degradation rates in the presence of Degussa P-25, which guaranteed longer lifetimes of the photogenerated electron/hole pairs. On the other hand, the rutile form of titania was reported to be the least efficient in the degradation of humic acid [14]. The results presented in this research also confirmed the effectiveness of Degussa P-25 as a successful photocatalyst for the degradation of humic acid. Merck $\mathrm{TiO}_{2}$ with its very low BET surface area and rutile form was found to have the lowest photocatalytic activity. 


\section{CONCLUSION}

Photocatalytic oxidation of natural organic matter, namely humic acids was carried out in UV-illuminated slurries of $\mathrm{TiO}_{2}$ under various conditions. The dependence of the kinetic parameters on the incident light intensity and the photocatalytic activities of $\mathrm{TiO}_{2}$ materials were compared in terms of pseudo first order and L-H kinetics. Both pseudo first order and L-H rates agreed well with each other in the ordering of the photocatalysts and were found to be decreasing as: Degussa P-25 > Millennium PC-500 > Millennium PC-100. However, depending on the light intensity L-H rate constants and their ordering showed dissimilarity when compared to that of pseudo first order.

Under constant irradiation conditions, ionic strength dependent changes in structure of humic acid did not alter the degradation efficiency trend of the photocatalyst specimens. The photodegradation rates obtained at two different electrolyte concentrations were similar (same order of magnitude) with slightly lower rates for $0.1 \mathrm{M}$ ionic strength. At constant irradiation in the presence of $0.01 \mathrm{M}$ ionic strength the rate constants for humic acid removal were found to be decreasing in the following order: Degussa P-25 > Millennium PC-500 > Hombikat UV-100 > Millennium PC-100 > Merck. Increasing the ionic strength to $0.1 \mathrm{M}$ did not change that order.

The results confirm the effectiveness of Degussa P25 as a photocatalyst for the degradation of humic acid. Merck with its very low BET surface area and rutile form was found to have the lowest photocatalytic activity.

Although pseudo first order reaction model is widely used for comparative purposes, it does not possess a detailed explanation of the reaction kinetics due to the fact that it does not cover adsorption properties. Depending on the presented results covering the evaluation of different kinetic models, a better understanding of the interconnection between intrinsic properties of photocatalysts and the light intensity requires further investigation.

\section{ACKNOWLEDGMENTS}

The authors greatly acknowledge the financial support provided by Research Fund of Bogazici University Project No: 03S107.

\section{REFERENCES}

[1] D. W. Bahnemann, J. Cunningham, M. A. Fox, E. Pelizzetti, P. Pichat, and N. Serpone, in Aquatic Surface and Photochemistry, (G. R. Helz, R. G. Zepp, D. G. Crosby, Eds.), Lewis, Boca Raton, 1994.

[2] O. Legrini, E. Oliveros, and A. Braun, Chem. Rev. 93 (1993), 671.
[3] M. Bekbolet and J. Environ, Sci. Health. 31 (1996), 845.

[4] M. Bekbolet and I. Balcioglu, Wat. Sci. Technol. 34 (1996), 73.

[5] M. Bekbolet, Z. Boyacioglu, and B. Ozkaraova, Wat. Sci. Technol. 38 (1998), 155.

[6] C. S. Uyguner and M. Bekbolet, The Fifth International Conference on $\mathrm{TiO}_{2}$ Photocatalytic Purification and Treatment of Water and Air, London, Ontario, Canada, 25-30 June, 2000, 181.

[7] D. Gonenc and M. Bekbolet, Wat. Sci. Technol. 44 (2001), 205.

[8] M. Bekbolet, A. S. Suphandag, and C. S. Uyguner, J. Photochem. Photobiol. A: Chem. 148 (2002), 121.

[9] B. R. Eggins, F. L. Palmer, and J. A. Byrne, Wat. Res. 31 (1997), 1223.

[10] X. Z. Li, C. M. Fan, and Y. T. Sun, Chemosphere 48 (2002), 453.

[11] F. L. Palmer, B. R. Eggins, and H. M. Coleman, J. Photochem. Photobiol. A: Chem. 148 (2002), 137.

[12] Y. Cho and W. Choi, J. Photochem. Photobiol. A: Chem. 148 (2002), 129.

[13] R. Al-Rasheed and D. J. Cardin, Chemosphere 51 (2003a), 925.

[14] R. Al-Rasheed and D. J. Cardin, Appl. Catal. A: General 8501 (2003b), 1.

[15] J. Wiszniowski, D. Robert, J. S. Gorska, K. Miksch, and J. V. Weber, Int. J. Photoenergy 5 (2003), 69.

[16] J. G. Sczechowski, C. A. Koval, and R. D. Noble, J. Photochem. Photobiol. A: Chem. 74 (1993), 273.

[17] L. Vincze L. and T. J. Kemp, J. Photochem. Photobiol. A: Chem. 87 (1995), 257.

[18] S. Uphadya and D. F. Ollis, J. Phys. Chem. B. 101 (1997), 2625.

[19] N. Serpone N. and A. V. Emeline, Int. J. Photoenergy 4 (2002), 91.

[20] K. Urano, H. Wada, and T. Takemasa, Wat. Res. 17 (1983), 1797.

[21] C. G. Hachard and C. A. Parker, Proc. R. Soc. Lond. A. 235 (1956), 518.

[22] C. S. Turchi and D. F. Ollis, J. Catal. 119 (1989), 483.

[23] C. S. Turchi and D. F. Ollis, J. Catal. 122 (1990), 178.

[24] A. Mills and S. Morris S., J. Photochem. Photobiol. A: Chem. 71 (1993), 75.

[25] Y. B. Meng, X. Hunag, Y. Wu, X. Wang, and Y. Qian, Environ. Pollution 117 (2002), 307.

[26] A. Rachel, M. Sarakha, M. Subrahmanyam, and P. Boule, Appl. Catal. B: Environ. 37 (2002), 293.

[27] T. Ohno, K. Tokilda, S. Higashida, and M. Matsumura, Appl. Catal. B: General 244 (2003), 383.

[28] A. V. Emeline, V. Ryabchuk, and N. Serpone, J. Photochem. Photobiol. A: Chem. 133 (2000), 89.

[29] Y. M. Xu and C. H. Langford, J. Photochem. Photobiol. A: Chem. 133 (2000), 67.

[30] D. F. Ollis, E. Pelizzetti, and N. Serpone, Environ. Sci. Technol. 25 (1991), 1523. 
[31] H. Al Ekabi, N. Serpone, Photocatalysis. Fundamentals and Application, (N. Serpone, E. Pelizzetti, Eds.), Wiley, New York, 1989, 457.

[32] A. Mills, R. H. Davies, and D. Worsley, Chem. Soc. Rev. 22 (1993), 417.

[33] A. A. Khodja, B. Lavedrine, C. Richard, and T. Sehili, Int. J. Photoenergy 4 (2002), 147.

[34] M. Anpo, Catalysis Surveys from Japan 1 (1997), 169.

[35] P. Cornel, R. Summers, and P. Roberts, J. Colloid Interface Sci. 110 (1986), 149.
[36] A. Mills and S. Le Hunt, J. Photochem. Photobiol. A: Chem. 108 (1997), 1.

[37] J. Guillard, J. Disdier, J. Herrmann, J. M. Lehaut, C. Chopin, T. Malato, and S. Blanco, J. Catal. Today 54 (1999), 217.

[38] S. T. Martin, H. Hermann, W. Choi, and M. R. Hoffmann, J. Chem. Soc. Faraday Trans. 90 (1994), 3315. 


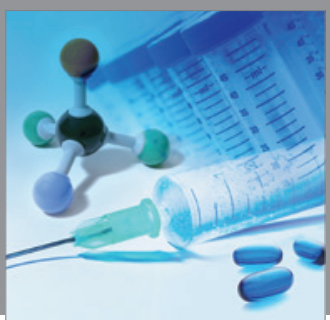

International Journal of

Medicinal Chemistry

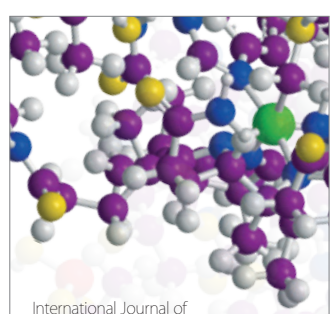

Carbohydrate Chemistry

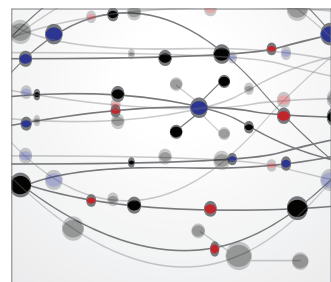

The Scientific World Journal
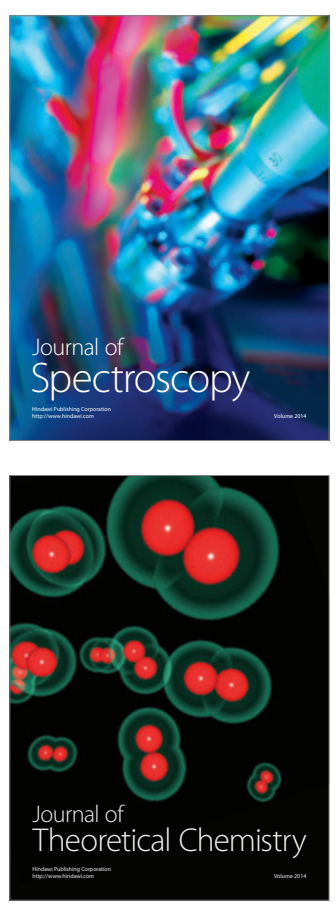
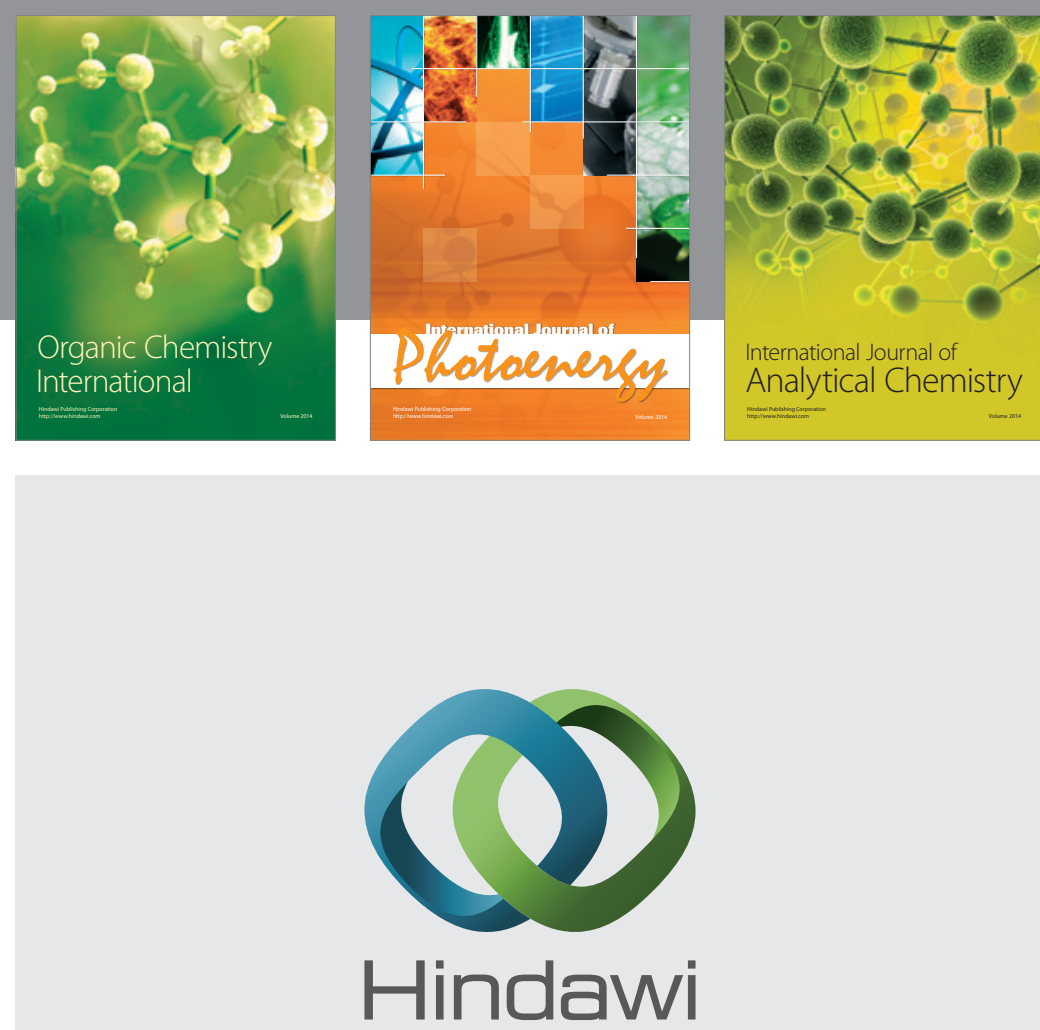

Submit your manuscripts at

http://www.hindawi.com
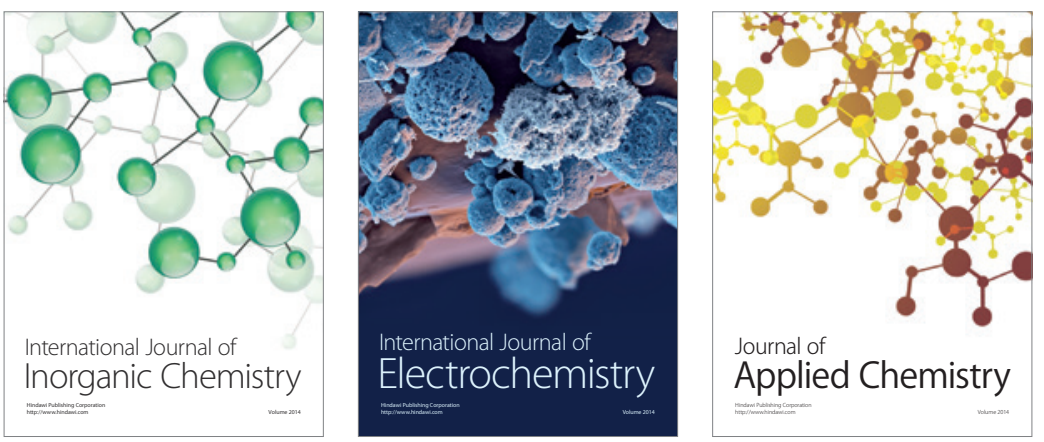

Journal of

Applied Chemistry
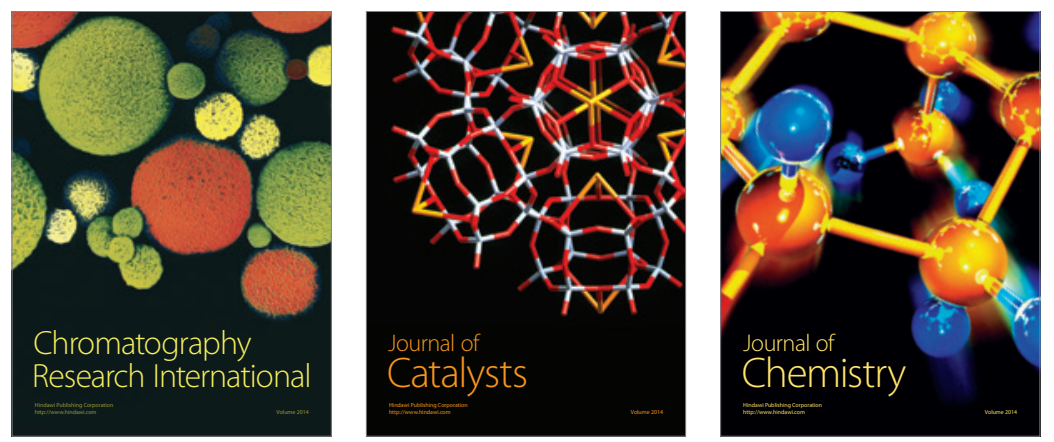
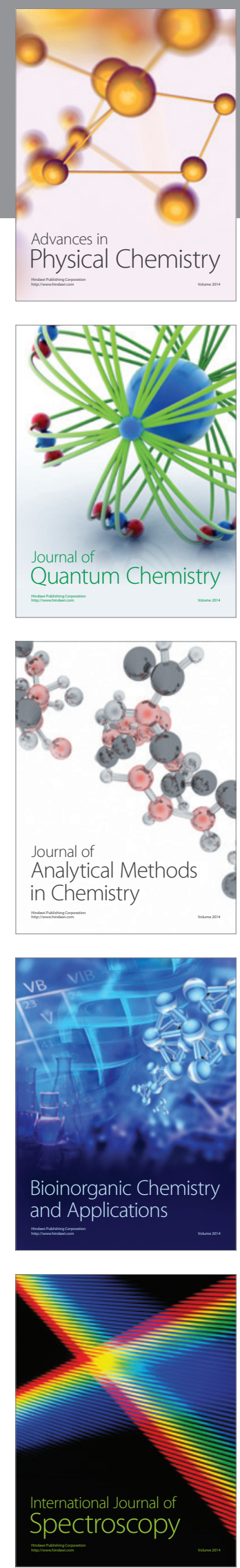